\title{
BMJ Open Association of platelet-to-lymphocyte count ratio with myocardial reperfusion and major adverse events in patients with acute myocardial infarction: a two- centre retrospective cohort study
}

Ailifeire Maimaiti, Yang Li, Yong-Tao Wang, Xiang Yang, Xiao-Mei Li, Yi-Ning Yang, Yi-Tong Ma

To cite: Maimaiti A, Li Y, Wang Y-T, et al. Association of platelet-to-lymphocyte count ratio with myocardial reperfusion and major adverse events in patients with acute myocardial infarction: a two-centre retrospective cohort study. BMJ Open 2019;9:e025628. doi:10.1136/ bmjopen-2018-025628

- Prepublication history for this paper is available online. To view these files, please visit the journal online (http://dx.doi. org/10.1136/bmjopen-2018025628).

Received 02 August 2018 Revised 24 July 2019 Accepted 30 July 2019

Check for updates

(C) Author(s) (or their employer(s)) 2019. Re-use permitted under CC BY-NC. No commercial re-use. See rights and permissions. Published by BMJ.

Department of Cardiology, First Affiliated Hospital of Xinjiang Medical University, Urumqi, China

Correspondence to Professor Yi-Tong Ma; myt-xj@163.com

\section{ABSTRACT}

Objective Insufficient myocardial reperfusion for patients with acute myocardial infarction (AMI) during primary percutaneous coronary intervention (PPCl) has a great influence on prognosis. The aim of this study was to investigate the association of the platelet-to-lymphocyte ratio (PLR) with myocardial reperfusion and in-hospital major adverse cardiac events (MACEs) in patients with AMI undergoing $\mathrm{PPCl}$.

Design Retrospective cohort study.

Setting Patients and researchers from two tertiary hospitals.

Participants A total of 445 consecutive AMI patients who underwent PPCI between January 2015 and December 2017 were enrolled. Patients were divided into two groups based on the PLR value: patients with PLR values in the third tertile were defined as the high-PLR group ( $n=150)$, and those in the lower two tertiles were defined as the low-PLR group ( $n=295)$. Explicit criteria for inclusion and exclusion were applied.

Interventions No interventions.

Primary and secondary outcome measures Primary outcome measures were defined as cardiovascular death, reinfarction or target vessel revascularisation. Secondary outcome measures were defined as stroke, non-lethal myocardial infarction, ventricular tachycardia/ventricular fibrillation and in-hospital mortality.

Results The high-PLR group had insufficient myocardial perfusion ( $23 \%$ vs $13 \%, p=0.003)$, greater postprocedural thrombolysis in myocardial infarction flow grade $(0-2)$ ( $17 \%$ vs $10 \%, p=0.037$ ), greater myocardial blush grade $(0-1)(11 \%$ vs $4 \%, p=0.007)$ and higher B-type natriuretic peptide (BNP) $(614 \pm 600$ vs $316 \pm 429, p<0.001)$ compared with the low-PLR group. Multivariate logistic regression analysis indicated that the independent risk factors for impaired myocardial perfusion were high PLR (OR 1.256, $95 \% \mathrm{Cl} 1.003$ to $1.579, \mathrm{p}=0.056$ ) and high BNP (OR 1.328, $95 \% \mathrm{Cl} 1.056$ to $1.670, p=0.015)$. The high-PLR group had significantly more MACEs ( $43 \%$ vs $32 \%, p=0.029)$.

Conclusions This study suggested that high PLR and BNP were independent risk factors for insufficient myocardial reperfusion in patients with AMI. Higher PLR was related to advanced heart failure and in-hospital MACEs in patients with AMl undergoing PPCl.
Strengths and limitations of this study

- The first multicentre retrospective cohort study to examine the relationship between platelet-to-lymphocyte ratio (PLR) and myocardial reperfusion.

- We only included patients with left anterior descending branch vascular occlusion among patients with acute myocardial infarction.

- We grouped the population according to PLR value.

- Our study population was small, and a larger sample size will be required for prospective clinical studies.

- This study focused on in-hospital screening and adverse events among participants and lacked longterm follow-up results.

\section{INTRODUCTION}

Acute myocardial infarction (AMI) is one of the leading causes of death worldwide.

1 Emergency primary percutaneous coronary intervention (PPCI) is the first choice for patients with AMI to restore blood flow. Studies have shown that early reperfusion can effectively reduce the myocardial infarct (MI) size and restore heart function. ${ }^{2}$ Although blood flow of the occluded vascular artery is restored (thrombolysis in myocardial infarction (TIMI) grade 3 after PPCI), many patients still have insufficient myocardial perfusion. ${ }^{3}$ This could result in severe myocardial ischaemia, malignant arrhythmia, haemodynamic deterioration and other adverse outcomes. ${ }^{4-7}$ The insufficient myocardial perfusion is mainly due to microvascular obstruction (MVO) ${ }^{8}$ The main mechanism of MVO is ischaemia-reperfusion (IR) injury to coronary arteries. This injury involves multiple pathophysiological factors (calcium overload, oxidative stress, inflammation, and mitochondrial dysfunction) and multiple players (cardiomyocytes, microvasculature, 
inflammatory cells and platelets), making it a complex system. ${ }^{9}$ Therefore, it is necessary to find the risk factors that affect myocardial reperfusion.

Platelet activation plays a critical role in the formation of acute thrombosis of coronary arteries. ${ }^{10}$ Increased platelet count is associated with the MI size in AMI patients and can lead to adverse cardiovascular events. ${ }^{11}$ The inflammatory response plays an important role in the formation of atherosclerotic plaques and myocardial IR injury. Studies have shown that decreased lymphocyte count was associated with increased mortality in patients with AMI. ${ }^{12-14}$ Previous studies have found that platelet-to-lymphocyte ratio (PLR) can be used as a predictor of long-term mortality and is an independent risk factor for no reflow after PPCI and increased mortality in hospital, and the increase in PLR is positively correlated with the 6-month all-cause mortality in ST-elevation myocardial infarction (STEMI) patients. ${ }^{15-18}$

Studies have shown that the presence of MVO after PPCI as assessed by TIMI flow post-PPCI and myocardial blush grade (MBG) have all strongly been linked with worse outcomes in patients with AMI. ${ }^{19} 20$ The index of microcirculatory resistance (IMR) is a parameter for quantifying microcirculatory resistance. There are significant differences in the microvascular blood flow between the left anterior descending branch (LAD) and left circumflex branch, as well as the right coronary artery. ${ }^{21}$ Although previous studies have investigated the relationship between PLR and AMI, they have ignored the influence of myocardial ischaemic adaptation in different coronary arteries on myocardial reperfusion. To avoid the influence of this variation on the results, we only included AMI patients with proximal LAD blocking. Thus, this study intends to explore the effects of PLR on myocardial reperfusion and adverse events in patients with AMI and to provide guidance for the improvement of reperfusion therapy.

\section{MATERIAL AND METHODS \\ Participants}

This study is a multiple-centre retrospective cohort study. A total of 445 consecutive patients with AMI from two hospitals seen between January 2015 and December 2017 were reviewed. We analysed the clinical and angiographic data of consecutive patients diagnosed with AMI. The inclusion criteria were as follows: (1) they were eligible for the diagnostic criteria of STEMI; (2) there was $\leq 12$ hours from the onset of symptoms to PPCI; (3) the results of angiography confirmed that the infarcted blood vessel was the proximal LAD; and (4) complete clinical data were collected. The exclusion criteria were as follows: (1) active infection; (2) history of systemic infectious diseases in the previous 2 weeks; (3) malignant tumour; (4) hepatopathy; (5) chronic tuberculosis history; (6) history of heart failure; (7) history of percutaneous coronary intervention (PCI); and (8) long-term oral antiplatelet or statin drugs. All patients received $300 \mathrm{mg}$ of aspirin and $600 \mathrm{mg}$ clopidogrel or $180 \mathrm{mg}$ of ticagrelor before PPCI.
This study protocol conformed to the principles and guidelines of the Declaration of Helsinki. All participants or their close relatives provided written informed consent for participation before data collection.

\section{Clinical data collection}

Clinical data were collected from the medical records of hospitals by two physicians independently. Basic information: hospital number, telephone number and so on and medical history and personal history: hypertension and grade, diabetes, hyperlipidaemia, stroke history, prehospital medication history and smoking history. Venous blood samples were drawn before PPCI. Blood test parameters and other measurements were determined by standard laboratory methods. Records of blood routine before PPCI: biochemical measurements, myocardial enzymes and B-type natriuretic peptide (BNP). Cardiac ultrasound was done after PPCI. The TIMI and MBG grades of patients were recorded by two interventional doctors in a blind manner. The number of diseased blood vessels, sizes of the stents, number of clots and use of tirofiban were determined by operation records.

\section{Clinical definitions}

The study population was divided into tertiles according to the PLR values at admission. High PLR (group 1, $\mathrm{n}=150)$ was defined as a value in the third tertile $(\geq 165.33)$ and low PLR (group 2, n=295) as a value in the lower two tertiles $(<165.33)$. Cardiovascular mortality was defined as unexplained sudden death, death due to AMI or malignant arrhythmia. Reinfarction was defined based on the universal definition of MI guidelines. Non-lethal myocardial infarction was defined as type 1 or type 2 myocardial infarction according to guidelines. ${ }^{22}$ Major adverse cardiac events (MACEs) were defined as cardiovascular death, reinfarction or target vessel revascularisation.

Insufficient myocardial perfusion was defined as a postoperative TIMI grade less than 3 or a TIMI grade of 3 but with an MBG classification less than $2 .{ }^{23}$

\section{Statistical analysis}

All data were analysed by SPSS V.24.0 for Windows. Continuous variables are presented as the mean \pm SD. If two groups of quantitative data were consistent with the normal distribution, then they were compared by the independent sample $t$ test . If they did not fit the normal distribution, then they were compared by Wilcoxon's rank test. Two groups of count data were compared by the $\chi^{2}$ test or, if the frequency was lower than 5, Fisher's exact test. A backward stepwise multivariate logistic regression analysis was performed to identify independent predictors of insufficient myocardial perfusion. Statistical significance was defined as $\mathrm{p}<0.05$.

\section{Patient and public involvement}

Participants were not involved in the study design, recruitment, implementation, article writing or data collection. Patients did not incur additional medical burden in the study. The results of the study will be disseminated to 


\begin{tabular}{|c|c|c|c|}
\hline & $\begin{array}{l}\text { High PLR } \\
(n=150)\end{array}$ & $\begin{array}{l}\text { Low PLR } \\
(\mathrm{n}=295)\end{array}$ & $P$ value \\
\hline Age, years $x \pm s$ & $62.2 \pm 14.1$ & $59.5 \pm 12.2$ & 0.117 \\
\hline Male, n (\%) & $93(62)$ & $196(66.4)$ & 0.335 \\
\hline Hypertension, n (\%) & $80(53.3)$ & $160(54.2)$ & 0.856 \\
\hline Diabetes, n (\%) & $33(22)$ & $80(27.1)$ & 0.241 \\
\hline Stroke, n (\%) & $13(8.7)$ & $20(6.8)$ & 0.473 \\
\hline Smoking, n (\%) & $57(38)$ & $130(44.1)$ & 0.220 \\
\hline $\begin{array}{l}\text { Hyperlipidaemia, } \\
\text { n (\%) }\end{array}$ & $6(4)$ & $16(5.4)$ & 0.513 \\
\hline Killip class $\geq 1 \mathrm{l}, \mathrm{n}(\%)$ & $129(86 \%)$ & $220(74.6 \%)$ & 0.006 \\
\hline $\begin{array}{l}\text { Ejection fraction, } \\
x \% \pm s\end{array}$ & $34.8 \pm 6.0$ & $37.4 \pm 7.1$ & 0.006 \\
\hline $\begin{array}{l}\text { Symptom onset to } \\
\text { intervention } \\
\text { (hours) }\end{array}$ & $7.00 \pm 4.83$ & $7.15 \pm 4.80$ & 0.608 \\
\hline$\geq 6$ & 66 (44.0\%) & $131(44.4 \%)$ & 0.935 \\
\hline
\end{tabular}

PLR, platelet-to-lymphocyte ratio.

all patients and medical institutions through academic conferences, news reports and health publicity.

\section{RESULTS}

The baseline characteristics of the two groups are presented in table 1. A total of 445 patients (136 from one medical centre, 309 from the other) were eligible. High-PLR patients were admitted to hospital with a significantly higher Killip class than low-PLR patients ( $86 \%$ vs $74.6 \%, p=0.006)$. The left ventricular ejection fraction of patients in the high-PLR group was significantly lower than that in the low-PLR group $(34.8 \% \pm 6.0$ vs $37.4 \% \pm 7.1, \mathrm{p}=0.006)$. Gender, hypertension, diabetes, history of stroke, smoking, hyperlipidaemia and time from symptom onset to intervention were not significantly different between the two groups $(p>0.05)$.

The laboratory data of the two groups are presented in table 2 . The preoperative white cell count (WCC) $(9.5 \pm 4.1$ vs $9.0 \pm 3.2, p=0.044)$ and red cell distribution width (RDW) $(13.6 \pm 3.1$ vs $13.2 \pm 2.3, p=0.026)$ in the low-PLR group were significantly lower. The peak values of BNP $(614 \pm 610 \mathrm{pg} /$ $\mathrm{mL}$ vs $316 \pm 429 \mathrm{pg} / \mathrm{mL}, \mathrm{p}<0.001)$ and alanine aminotransferase $(64.4 \pm 84.4 \mathrm{U} / \mathrm{L}$ vs $52.1 \pm 60.0 \mathrm{U} / \mathrm{L}, \mathrm{p}=0.003)$ was significantly higher than in the high-PLR group. There was no significant difference in neutrophil count, monocyte count, haemoglobin, creatinine, total cholesterol, high-density lipoprotein cholesterol, low-density lipoprotein cholesterol, $\mathrm{C}$ reactive protein, peak cardiac troponin $\mathrm{T}(\mathrm{cTnT})$ or peak creatine kinase-myocardial band.

The angiographic and procedural characteristics of the two groups are presented in table 3 . In the high-PLR group, the average implanted stent diameter was
Table 2 Comparison of laboratory results

\begin{tabular}{|c|c|c|c|}
\hline & $\begin{array}{l}\text { High PLR } \\
(n=150)\end{array}$ & $\begin{array}{l}\text { Low PLR } \\
(\mathrm{n}=295)\end{array}$ & $P$ value \\
\hline$W C C \times 10^{9} / L(x \pm S)$ & $9.5 \pm 4.1$ & $9.0 \pm 3.2$ & 0.044 \\
\hline Neutrophil $\times 10^{9} / \mathrm{L}(\mathrm{x} \pm \mathrm{S})$ & $8.1 \pm 6.8$ & $6.5 \pm 6.2$ & 0.171 \\
\hline Platelet $\times 10^{9} / \mathrm{L}(\mathrm{x} \pm \mathrm{s})$ & $264.2 \pm 85.9$ & $203.5 \pm 74.6$ & 0.006 \\
\hline Lymphocyte $\times 10^{9} / \mathrm{L}(\mathrm{x} \pm \mathrm{S})$ & $1.15 \pm 0.47$ & $2.23 \pm 2.41$ & 0.081 \\
\hline Monocyte $\times 10^{9} / L(x \pm S)$ & $0.5 \pm 0.3$ & $1.0 \pm 4.6$ & 0.167 \\
\hline Haemoglobin $(g / L, x \pm s))$ & $129.6 \pm 23.7$ & $135.8 \pm 23.0$ & 0.524 \\
\hline $\operatorname{RDW}(\%, x \pm s)$ & $13.6 \pm 3.1$ & $13.2 \pm 2.3$ & 0.026 \\
\hline $\operatorname{ALT}(\mathrm{U} / \mathrm{L}, \mathrm{x} \pm \mathrm{S})$ & $64.4 \pm 84.4$ & $52.1 \pm 60.0$ & 0.003 \\
\hline Creatinine $(\mu \mathrm{mol} / \mathrm{L}, \mathrm{x} \pm \mathrm{s})$ & $76.3 \pm 30.8$ & $78.4 \pm 36.3$ & 0.336 \\
\hline $\begin{array}{l}\text { Total cholesterol }(\mu \mathrm{mol} / \mathrm{L} \text {, } \\
\mathrm{X} \pm \mathrm{S})\end{array}$ & $4.1 \pm 1.0$ & $4.1 \pm 1.1$ & 0.198 \\
\hline $\begin{array}{l}\mathrm{HDL} \text {-cholesterol }(\mu \mathrm{mol} / \mathrm{L}, \\
\mathrm{X} \pm \mathrm{S})\end{array}$ & $1.1 \pm 0.3$ & $1.0 \pm 0.5$ & 0.446 \\
\hline $\begin{array}{l}\text { LDL-cholesterol }(\mu \mathrm{mol} / \mathrm{L} \text {, } \\
\mathrm{X} \pm \mathrm{S})\end{array}$ & U. & $2.0 \pm 0.9$ & 0.880 \\
\hline $\mathrm{CRP}(\mathrm{mg} / \mathrm{L}, \mathrm{x} \pm \mathrm{s})$ & $17.8 \pm 32.0$ & $16.7 \pm 26.6$ & 0.611 \\
\hline Peak cTnT (U/L, X $\pm S)$ & $5.7 \pm 4.0$ & $4.9 \pm 3.8$ & 0.236 \\
\hline Peak CK-MB (U/L, X $\pm S)$ & $242 \pm 382$ & $226 \pm 335$ & 0.498 \\
\hline $\mathrm{BNP}(\mathrm{pg} / \mathrm{mL}, \mathrm{x} \pm \mathrm{s})$ & $614 \pm 600$ & $316 \pm 429$ & $<0.001$ \\
\hline
\end{tabular}

ALT, alanine aminotransferase; BNP, brain natriuretic peptide; CK$\mathrm{MB}$, creatine kinase-myocardial band; CRP, C-reactive protein; cTnT, cardiac troponin T; HDL, high-density lipoprotein; LDL, lowdensity lipoprotein; PLR, platelet-to-lymphocyte ratio; RDW, red cell distribution width; WCC, white cell count.

significantly smaller $(2.93 \pm 0.47$ vs $2.96 \pm 0.40, \mathrm{p}=0.015)$, thrombus aspiration was higher ( $64 \%$ vs $52 \%, \mathrm{p}=0.015)$ and platelet count was higher ( $264.2 \pm 85.9$ vs $203.5 \pm 74.6$, $\mathrm{p}=0.006$ ). The patients in the high-PLR group had significantly lower postprocedural TIMI grade (17\% vs $10 \%$, $\mathrm{p}=0.037)$ and MBG stage ( $11 \%$ to $4 \%, \mathrm{p}=0.007)$ after PCI. In the high-PLR group, the incidence of insufficient myocardial perfusion was significantly increased $(23 \%$ vs $13 \%, \mathrm{p}=0.003$ ). There was no significant difference in the number of diseased vessels, the number of stents used, the average implanted stent length or the use of tirofiban. The MACEs in the high-PLR group were significantly more common ( $43 \%$ vs $32 \%, \mathrm{p}=0.004$ ). There was no significant difference in non-lethal myocardial infarction, stroke, in-hospital mortality or ventricular tachycardia/ ventricular fibrillation (table 4).

We performed univariate logistic regression analysis of factors affecting the sufficiency of myocardial perfusion, and the results showed that high BNP (OR 1.329, 95\% CI 1.057 to $1.672(\mathrm{p}=0.015)$ and high PLR (OR $1.254,95 \%$ CI 1.001 to $1.571 \quad(\mathrm{p}=0.051)$ contributed to the insufficient myocardial perfusion of PPCI patients. We included all factors to perform multivariate logistic regression analysis. We found that high PLR (OR 1.256, 95\% CI 1.003 to $1.579(\mathrm{p}=0.056)$ and high BNP (OR 1.328, 95\% CI 1.056 
Table 3 Angiographic and procedural characteristics of patients

\begin{tabular}{|c|c|c|c|}
\hline & $\begin{array}{l}\text { High PLR } \\
(n=150)\end{array}$ & $\begin{array}{l}\text { Low PLR } \\
(n=295)\end{array}$ & $P$ value \\
\hline \multicolumn{4}{|l|}{$\begin{array}{l}\text { Number of diseased } \\
\text { vessels }\end{array}$} \\
\hline $1, \mathrm{n}(\%)$ & $54(36)$ & $103(35)$ & 0.821 \\
\hline$\geq 2, \mathrm{n}(\%)$ & $96(64)$ & $192(65)$ & \\
\hline \multicolumn{4}{|l|}{ Number of stent use } \\
\hline $1, \mathrm{n}(\%)$ & $66(44)$ & $119(40)$ & 0.459 \\
\hline$\geq 2, n(\%)$ & $84(56)$ & $176(60)$ & \\
\hline $\begin{array}{l}\text { Stent length, average } \\
(\mathrm{mm}, \mathrm{X} \pm \mathrm{s})\end{array}$ & $26.4 \pm 8.1$ & $25.9 \pm 6.3$ & 0.067 \\
\hline $\begin{array}{l}\text { Stent diameter, } \\
\text { average }(\mathrm{mm}, \mathrm{x} \pm \mathrm{s})\end{array}$ & $2.93 \pm 0.47$ & $2.96 \pm 0.40$ & 0.015 \\
\hline Tirofiban use, n (\%) & $135(90)$ & 271 (92) & 0.511 \\
\hline $\begin{array}{l}\text { Thrombus aspiration, } \\
\mathrm{n}(\%)\end{array}$ & $96(64)$ & 153 (52) & 0.015 \\
\hline \multicolumn{4}{|l|}{$\begin{array}{l}\text { Postprocedural TIMI } \\
\text { grade }\end{array}$} \\
\hline $0-2, \mathrm{n}(\%)$ & $25(17)$ & $29(10)$ & 0.037 \\
\hline $3, \mathrm{n}(\%)$ & $125(83)$ & $266(90)$ & \\
\hline \multicolumn{4}{|l|}{ MBG grade } \\
\hline 0 and $1, \mathrm{n}(\%)$ & $16(11)$ & $12(4)$ & 0.007 \\
\hline 2 and $3, \mathrm{n}(\%)$ & $134(89)$ & $283(96)$ & \\
\hline $\begin{array}{l}\text { Insufficient } \\
\text { myocardial } \\
\text { reperfusion, n (\%) }\end{array}$ & $35(23)$ & 37 (13) & 0.003 \\
\hline
\end{tabular}

MBG, myocardial blush grade; PLR, platelet-to-lymphocyte ratio; TIMI, thrombolysis in myocardial infarction.

to $1.670(p=0.015)$ were independent risk factors for insufficient myocardial perfusion (table 5 ).

\section{DISCUSSION}

In our study, after controlling for the effects of different coronary artery lesions on insufficient myocardial

Table 4 In-hospital cardiac events and complications

\begin{tabular}{lccc}
\hline & $\begin{array}{l}\text { High PLR } \\
(\mathbf{n = 1 5 0 )}\end{array}$ & $\begin{array}{l}\text { Low PLR } \\
(\mathbf{n = 2 9 5 )}\end{array}$ & $\begin{array}{l}\mathbf{P} \\
\text { value }\end{array}$ \\
\hline MACEs, n (\%) & $64(43)$ & $95(32)$ & 0.029 \\
$\begin{array}{l}\text { Non-lethal myocardial } \\
\text { infarction, n (\%) }\end{array}$ & $6(4)$ & $7(2)$ & 0.335 \\
$\begin{array}{l}\text { Stroke, n (\%) } \\
\text { In-hospital mortality, n (\%) }\end{array}$ & $41(7)$ & $18(6)$ & 0.619 \\
$\begin{array}{l}\text { Ventricular tachycardia/ } \\
\text { ventricular fibrillation, } \mathrm{n}(\%)\end{array}$ & $42(28)$ & $69(1)$ & 0.186 \\
\hline
\end{tabular}

MACEs, major adverse cardiac events (cardiovascular death, reinfarction and target vessel revascularisation); PLR, platelet-tolymphocyte ratio. reperfusion, it was found that high PLR and BNP were independent risk factors for insufficient myocardial reperfusion after PPCI for patients with AMI. Earlier studies have shown that high PLR is significantly correlated with MACEs, Killip grade, ejection fraction (EF) value, platelet count, RDW, length/diameter of stent implantation and thrombus aspiration in patients with AMI.

The pathophysiological mechanism of insufficient myocardial reperfusion is that microvascular blood flow is hindered by MVO. ${ }^{924}$ The aetiological mechanisms are that: (1) platelet activation and adhesion, which increase cell death and aggregation, can affect myocardial flow; (2) increased endothelial permeability and subsequent recruitment of inflammatory cells into the site of infarction can lead to acute IR injury ${ }^{25}$; (3) mitochondrial dysfunction caused by calcium overload and Receiver Operating Characteristic (ROS) accumulation can also lead to IR injury. ${ }^{26}$ PLR as an index contains information on platelet and lymphocyte counts in patients with AMI. It is more significant in predicting insufficient myocardial reperfusion after PPCI in patients with AMI than platelet or lymphocyte count. Platelets play a key role in the pathogenesis of AMI through the formation of platelet-fibrin complexes. ${ }^{10}$ Increasing platelet count has been associated with the occurrence of AMI. ${ }^{27}$ Activating platelets adhere to vascular endothelial cells and produce inflammatory cytokines, leading to mononuclear cell adhesion and migration, accelerating the progression of atherosclerotic plaques. These activating adhesion molecules and chemokines promote the activation of white cell count and produce reactive oxygen species and matrix metalloproteinases, causing plaque instability in atherosclerotic plaques. ${ }^{28}$ Gary et al found that increasing platelet volume can change blood viscosity and promote inflammation. ${ }^{29}$ Temiz et al found that increasing platelet activity was associated with a high incidence of cardiovascular events in hospital. ${ }^{30}$ These studies indicated that the increase in platelet count was significantly correlated with the occurrence of AMI and poor prognosis.

During the pathogenetic process of AMI, lymphocytes enter the IR-injured myocardial tissue and secrete interleukin-10 to inhibit the inflammatory response. The lymphocytes also secrete tissue factor (TF) and mmp-1 to promote the coagulation reaction. Studies have shown a correlation between decreased lymphocyte count and increased frequency of cardiovascular events in patients with AMI. ${ }^{12} 31$ A decrease in lymphocyte count caused by stress can increase the incidence of death in patients with AMI. ${ }^{32}$ Therefore, PLR may become a new indicator of thrombus formation, inflammatory state and short-term and long-term adverse outcomes of patients with AMI.

Based on the TIMI class after PCI, Yildiz et $a \hat{l}^{32}$ divided acute STEMI patients into two groups: no-reflow and reflow. An analysis of routine blood examination before PCI and myocardial reperfusion showed that increasing the PLR value was an independent risk factor for the prediction of no-reflow in acute STEMI patients. ${ }^{33}$ Ayca et al used ROC curve analysis to show that a PLR $>137$ predicted adverse events for patients who had undergone 
Table 5 The independent predictors of insufficient myocardial reperfusion

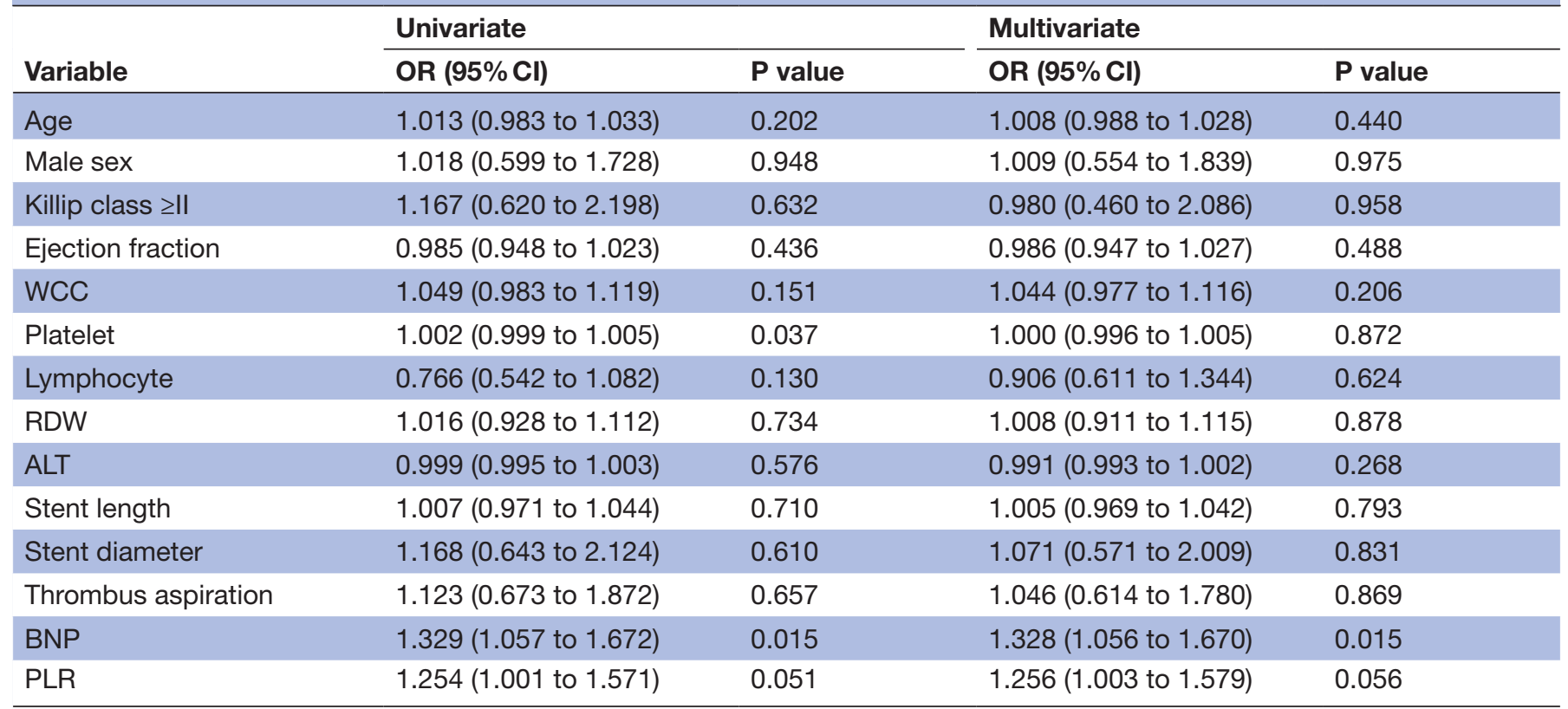

ALT, alanine aminotransferase; BNP, brain natriuretic peptide; PLR, platelet-to-lymphocyte ratio; RDW, red cell distribution width; WCC, white cell count.

PPCI, with a specificity of $67 \%$ and a sensitivity of $63 \% .^{34}$ Kurtul et $a l^{17}$ found that PLR was significantly associated with the severity and complexity of coronary atherosclerosis in ACS patients who underwent PPCI. A higher PLR value was an independent predictor of an intermediate to high SXscore. ${ }^{17}$ Preintervention PLR was a strong and independent predictor of slow flow/no-reflow after PPCI in patients with acute STEMI. ${ }^{35}$ Ugur et al found that higher PLR was associated with an increased risk for in-hospital adverse outcomes and 6 month all-cause mortality with STEMI after PPCI. ${ }^{18}$ PLR should be incorporated into the clinical practice of risk stratification for patients admitted with STEMI who undergo primary PCI.

Our study found that high BNP was an independent risk factor for insufficient myocardial reperfusion after PPCI in patients with AMI. BNP is a quantitative marker of heart failure that is significantly correlated with left ventricular systolic function. ${ }^{36}$ During the process of hypoxia, oedematosis and necrosis at the myocardial infarction site, cardiomyocytes can produce BNP through the transcription of the Natriuretic peptide precursor B (NPPB) gene in the endoplasmic reticulum. ${ }^{37}$ When occlusion of the proximal LAD causes hypoxia and oedema of myocardial cells, BNP will be secreted in large quantities. Elevated BNP leads to plasma concentrations of angiotensin II and endothelin-1 by activating the renin angiotensin system. ${ }^{38}$ This will further aggravate the reperfusion of ischaemic myocardium at the infarct site. BNP has been shown to be an independent risk factor for IR injury in ST-segment elevation AMI patients. ${ }^{39}$ Studies have shown that the increased secretion of BNP during myocardial ischaemia is mainly regulated by the PI3K/Akt/p70s6k signalling pathway, which has a protective effect on the myocardium. ${ }^{40}$ This change is an adaptation of myocardial cells to ischaemia. Therefore, the BNP level can reflect the severity of myocardial ischaemia, which is strongly related to insufficient myocardial reperfusion. This study also found that thrombus aspiration was associated with insufficient myocardial reperfusion in patients with AMI. At present, the role of thrombus aspiration in PPCI patients is still controversial. ${ }^{41}$ The TAPAS (Thrombus Aspiration during Percutaneous CoronaryIntervention in Acute Myocardial Infarction Study) study showed that thrombus aspiration in PPCI patients did not reduce the total mortality at 30 days or 1 year. ${ }^{43}$ The TOTAL (ThrOmbecTomy with PCI versus PCI ALone in Patients with STEMI) study showed that the main endpoints followed up for 180 days ( $6.9 \%$ vs $7.0 \%$; $=0.86$ ) and 1 year $(7.8 \%$ vs $7.8 \%$; $=0.991)$ were not significantly different between the thrombus aspiration group and non-thrombus aspiration group. ${ }^{44}$ In addition, a study showed that thrombus aspiration did not improve myocardial reperfusion in patients with long-term ischaemia, small infarction area and light thrombosis. ${ }^{45}$ Hoole et al observed changes in IMR during PPCI and found that patients with relatively light thrombosis were prone to distal embolisation after thrombus aspiration, which would lead to microcirculation injury. ${ }^{46}$

Limitations of this study: (1) the sample size of this study was small, and prospective clinical studies with larger samples are needed to confirm the findings. (2) This study did not evaluate the decline in the ECG ST segment after emergency PCI, but a former study showed that the ST fallback was consistent with the MBG grading results. (3) Long-term follow-up was not conducted, and further study is needed to evaluate the long-term prognosis of patients with AMI. 


\section{CONCLUSION}

In conclusion, our study showed that high PLR and BNP on hospital admission could be used as independent risk factors for predicting insufficient myocardial reperfusion after PPCI in AMI patients with proximal LAD occlusion. High PLR is associated with higher MACE incidence during hospitalisation. PLR and BNP are convenient and inexpensive to detect in clinical practice. Clinicians can grade the risk of insufficient myocardial reperfusion in patients with AMI according to the PLR value.

Acknowledgements We would like to thank our colleagues for their help. We would also like thank all the patients for their support.

Contributors $\mathrm{AM}$ and $\mathrm{YL}$ contributed equally to this work. AM and Y-TW were responsible for the statistical analysis and write this paper. $Y L$ and $X Y$ provided the database. X-ML and Y-NY critically revised the paper for important intellectual content. Y-TM was accountable for all aspectsof the work and fund collection.

Funding This work was supported by National Natural Science Foundation of China (NSFC) grant number 2017E0269.

Competing interests None declared.

Patient consent for publication Parental/guardian consent obtained.

Provenance and peer review Not commissioned; externally peer reviewed.

Data availability statement Data are available on reasonable request.

Open access This is an open access article distributed in accordance with the Creative Commons Attribution Non Commercial (CC BY-NC 4.0) license, which permits others to distribute, remix, adapt, build upon this work non-commercially, and license their derivative works on different terms, provided the original work is properly cited, appropriate credit is given, any changes made indicated, and the use is non-commercial. See: http://creativecommons.org/licenses/by-nc/4.0/.

\section{REFERENCES}

1. Reed GW, Rossi JE, Cannon CP. Acute myocardial infarction. The Lancet 2017;389:197-210.

2. Tra J, van der Wulp I, de Bruijne MC, et al. Exploring the treatment delay in the care of patients with ST-elevation myocardial infarction undergoing acute percutaneous coronary intervention: a crosssectional study. BMC Health Serv Res 2015;15:340.

3. Ndrepepa G, Tiroch K, Fusaro M, et al. 5-Year prognostic value of no-reflow phenomenon after percutaneous coronary intervention in patients with acute myocardial infarction. J Am Coll Cardiol 2010;55:2383-9.

4. Haeck JDE. Relationship between myocardial reperfusion, infarct size, and mortality. JACC Cardiovasc Interv 2013;6.

5. Stone GW, Peterson MA, Lansky AJ, et al. Impact of normalized myocardial perfusion after successful angioplasty in acute myocardial infarction. J Am Coll Cardiol 2002;39:591-7.

6. Gibson CM, Cannon CP, Murphy SA, et al. Relationship of TIMI myocardial perfusion grade to mortality after administration of thrombolytic drugs. Circulation 2000;101:125-30.

7. Hoffmann R, Haager P, Arning J, et al. Usefulness of myocardial blush grade early and late after primary coronary angioplasty for acute myocardial infarction in predicting left ventricular function. Am $J$ Cardiol 2003;92:1015-9.

8. Krug A, Rochemont Du Mesnil de, Korb G. Blood supply of the myocardium after temporary coronary occlusion. Circ Res 1966;19:57-62.

9. Hausenloy DJ, Botker HE, Engstrom T, et al. Targeting reperfusion injury in patients with ST-segment elevation myocardial infarction: trials and tribulations. Eur Heart J 2017;38:935-41.

10. Davì G, Patrono C, Giovanni D, Carlo P. Platelet activation and atherothrombosis. N Engl J Med 2007;357:2482-94.

11. Gibson CM, Karha J, Murphy SA, et al. Early and long-term clinical outcomes associated with reinfarction following fibrinolytic administration in the thrombolysis in myocardial infarction trials. $J$ Am Coll Cardiol 2003;42:7-16.

12. Horne BD, Anderson JL, John JM, et al. Which white blood cell subtypes predict increased cardiovascular risk? J Am Coll Cardiol 2005;45:1638-43.
13. Guasti L, Dentali F, Castiglioni L, et al. Neutrophils and clinical outcomes in patients with acute coronary syndromes and/or cardiac revascularisation. A systematic review on more than 34,000 subjects. Thromb Haemost 2011;106:591-9.

14. Bian C, Wu Y, Shi Y, et al. Predictive value of the relative lymphocyte count in coronary heart disease. Heart Vessels 2010;25:469-73.

15. Li W, Liu Q, Tang Y. Platelet to lymphocyte ratio in the prediction of adverse outcomes after acute coronary syndrome: a meta-analysis. Sci Rep 2017;7.

16. Azab B, Shah N, Akerman M, et al. Value of platelet/lymphocyte ratio as a predictor of all-cause mortality after non-ST-elevation myocardial infarction. J Thromb Thrombolysis 2012;34:326-34.

17. Kurtul A, Murat SN, Yarlioglues M, et al. Association of platelet-tolymphocyte ratio with severity and complexity of coronary artery disease in patients with acute coronary syndromes. Am J Cardiol 2014;114:972-8.

18. Ugur M, Gul M, Bozbay M, et al. The relationship between platelet to lymphocyte ratio and the clinical outcomes in ST elevation myocardial infarction underwent primary coronary intervention. Blood Coagul Fibrinolysis 2014;25:806-11.

19. Morishima I, Sone T, Okumura K, et al. Angiographic no-reflow phenomenon as a predictor of adverse long-term outcome in patients treated with percutaneous transluminal coronary angioplasty for first acute myocardial infarction. J Am Coll Cardiol 2000;36:1202-9.

20. Sorajja P, Gersh BJ, Costantini C, et al. Combined prognostic utility of ST-segment recovery and myocardial blush after primary percutaneous coronary intervention in acute myocardial infarction. Eur Heart J 2005;26:667-74.

21. Lee JM, Layland J, Jung JH, et al. Integrated physiologic assessment of ischemic heart disease in real-world practice using index of microcirculatory resistance and fractional flow reserve: insights from the International index of microcirculatory resistance registry. Circ Cardiovasc Interv 2015;8.

22. Thygesen K, Alpert JS, White HD, et al. Universal definition of myocardial infarction. J Am Coll Cardiol 2007;50:2173-95.

23. Niccoli G, Burzotta F, Galiuto L, et al. Myocardial no-reflow in humans. J Am Coll Cardiol 2009;54:281-92.

24. Niccoli G, Scalone G, Lerman A, et al. Coronary microvascular obstruction in acute myocardial infarction. Eur Heart $J$ 2016;37:1024-33.

25. Aurigemma C, Scalone G, Tomai F, et al. Persistent enhanced platelet activation in patients with acute myocardial infarction and coronary microvascular obstruction: clinical implications. Thromb Haemost 2014;111:122-30.

26. Hausenloy DJ, Chilian W, Crea F, et al. The coronary circulation in acute myocardial ischaemia/reperfusion injury: a target for cardioprotection. Cardiovasc Res 2019;115:1143-55.

27. Javadov S, Jang S, Parodi-Rullán R, et al. Mitochondrial permeability transition in cardiac ischemia-reperfusion: whether cyclophilin $\mathrm{D}$ is a viable target for cardioprotection? Cell Mol Life Sci 2017;74:2795-813.

28. Lindemann S, Krämer B, Seizer P, et al. Platelets, inflammation and atherosclerosis. J Thromb Haemost 2007;5 Suppl 1:203-11. null:.

29. Gary T, Pichler M, Belaj K, et al. Platelet-To-Lymphocyte ratio: a novel marker for critical limb ischemia in peripheral arterial occlusive disease patients. PLoS One 2013;8:e67688.

30. Temiz A, Gazi E, Güngör Ömer, et al. Platelet/lymphocyte ratio and risk of in-hospital mortality in patients with ST-elevated myocardial infarction. Med Sci Monit 2014;20:660-5.

31. Frangogiannis NG, Smith CW, Entman ML. The inflammatory response in myocardial infarction. Cardiovasc Res 2002;53:31-47.

32. Yildiz A, Yuksel M, Oylumlu M, et al. The utility of the plateletlymphocyte ratio for predicting no reflow in patients with STsegment elevation myocardial infarction. Clin Appl Thromb Hemost 2015;21:223-8.

33. Ommen SR, Gibbons RJ, Hodge DO, et al. Usefulness of the lymphocyte concentration as a prognostic marker in coronary artery disease. Am J Cardiol 1997;79:812-4.

34. Ayça B, Akin F, Okuyan E. Platelet to lymphocyte ratio as a prognostic marker in primary percutaneous coronary intervention. Platelets 2015;26:816.

35. Akboga MK, Canpolat U, Balci KG, et al. Increased platelet to lymphocyte ratio is related to slow coronary flow. Angiology 2016;67:21-6.

36. Abassi Z, Karram T, Ellaham S, et al. Implications of the natriuretic peptide system in the pathogenesis of heart failure: diagnostic and therapeutic importance. Pharmacol Ther 2004;102:223-41.

37. Hama N, Itoh H, Shirakami G, et al. Rapid ventricular induction of brain natriuretic peptide gene expression in experimental acute myocardial infarction. Circulation 1995;92:1558-64. 
38. Luodonpää M, Vuolteenaho O, Eskelinen S, et al. Effects of adrenomedullin on hypertrophic responses induced by angiotensin II, endothelin-1 and phenylephrine. Peptides 2001;22:1859-66.

39. Arakawa $\mathrm{K}$, Himeno H, Kirigaya J, et al. B-Type natriuretic peptide as a predictor of ischemia/reperfusion injury immediately after myocardial reperfusion in patients with ST-segment elevation acute myocardial infarction. Eur Heart J Acute Cardiovasc Care 2016;5:62-70.

40. Breivik L, Jensen A, Guvåg S, et al. B-Type natriuretic peptide expression and cardioprotection is regulated by Akt dependent signaling at early reperfusion. Peptides 2015;66:43-50.

41. Mahmoud KD, Zijlstra F, Felix Z. Thrombus aspiration in acute myocardial infarction. Nat Rev Cardiol 2016;13:418-28.

42. Jolly SS, James S, Džavík V, et al. Thrombus aspiration in STsegment-elevation myocardial infarction: an individual patient meta-analysis: thrombectomy Trialists collaboration. Circulation 2017;135:143-52.
43. Svilaas T, Vlaar PJ, van der Horst IC, et al. Thrombus aspiration during primary percutaneous coronary intervention. N Engl $J$ Med 2008;358:557-67.

44. Jolly SS, Cairns JA, Yusuf S, et al. Outcomes after thrombus aspiration for ST elevation myocardial infarction: 1-year followup of the prospective randomised total trial. The Lancet 2016;387:127-35.

45. Vandermolen S, Marciniak M, Byrne J, et al. Thrombus aspiration in acute myocardial infarction: concepts, clinical trials, and current guidelines. Coron Artery Dis 2016;27:233-43.

46. Hoole SP, Jaworski C, Brown AJ, et al. Serial assessment of the index of microcirculatory resistance during primary percutaneous coronary intervention comparing manual aspiration catheter thrombectomy with balloon angioplasty (impact study): a randomised controlled pilot study. Open Heart 2015;2:e000238. 